REVISTA CHILENA DE LITERATURA

Abril 2009, Número 74, 213 - 223

\title{
ASPECTOS IDEOLÓGICOS EN CINCO HORAS CON MARIO DE MIGUEL DELIBES
}

\author{
Fernando Larraz \\ GEXEL/ Universidad Autónoma de Barcelona \\ fernando.larraz@uab.cat
}

El éxito de público que obtuvo la novela Cinco horas con Mario en su primera edición a fines de 1966 se explica en gran medida por su fuerte componente ideológico. Se trataba de una obra de plena actualidad, en la que se apreciaba sin necesidad de una competencia lectora especial una apología de los emblemas políticos del momento: diálogo, reconciliación, tolerancia y libertad. No fue difícil para los lectores discernir los universos doctrinarios de los dos personajes principales y encontrar en ellos sendas objetivaciones de las tensiones entre inmovilistas y reformadores de todo tipo que caracterizan el ambiente cultural de la época. Es muy notorio el desprecio casi caricaturesco que el autor siente por su narradora, a quien hace depositaria de todos los defectos de los reaccionarios. El magistral estudio lingüístico desplegado en el soliloquio de Carmen se correspondía fielmente con el habla cotidiana y los clichés más recurrentes de la pequeña burguesía española, que aparece aquí retratada por un cerril conformismo, la heteronomía respecto de las consignas recibidas y un lenguaje empobrecedor y empobrecido. A todo ello se sumaba el empeño de Delibes por apuntarse al subjetivismo y superar los presupuestos de la novela realista a través de la originalidad compositiva. Delibes encontró en el monólogo de Carmen una fórmula para su discurso que determinó el cuidadoso manejo del tiempo, el espacio y la particular focalización. Del primero destaca el agudo contraste entre el tiempo del discurso (las "cinco horas" indicadas en el título) y los treinta años de historia de este matrimonio fracasado; las continuas analepsis con las que Carmen va alumbrando sucesivamente los rastros que su identidad encuentra en el pasado, calas significativas de su mediocridad y de su catadura moral; y, sobre todo, las reiteradas alusiones a los mismos sucesos que la obsesionan y que, a base de repetírselos han quedado solidificados como la costra de una personalidad formularia y en absoluto espontánea. El espacio escénico de la historia -el despacho de Mario, santuario de su cultura, del que Carmen ha estado desterrada a lo largo de su matrimonio, con el cuerpo del difunto presente- $\mathrm{y}$ el espacio social de esa ciudad de provincias son igualmente fundamentales para el funcionamiento de la novela. 
No es de extrañar que los primeros críticos se fijaran en la irreductible dualidad de los dos personajes como clave interpretativa de la novela. Para Gonzalo Sobejano, la novela es "el ejemplo del imposible entendimiento entre una mujer necia y simplista y un hombre inteligente y complejo, entre el dogma de fe y el amor de caridad, entre una España cerrada y una España abierta, entre la autoridad y la libertad, la costumbre inauténtica y el esfuerzo auténtico" (154).

En efecto, las hondas disimilitudes de ambos personajes invitan a una lectura fuertemente dicotómica de la novela, en la que Mario y Carmen quedan reducidos a poco más que arquetipos sociales. Delibes habría ensayado una visión microscópica de la trágica dialéctica de las dos Españas mediante su transposición a un matrimonio de provincias. La novela nos hablaría de dos maneras radicalmente diferentes de enfrentarse con la realidad, que derivan de unas condiciones sociopolíticas en las que la cultura es usada como propaganda, la educación es fuertemente sexista y han aparecido una serie de necesidades urgidas por la sociedad de consumo del último franquismo. En este contexto, la desbordada subjetividad de Carmen monopoliza el discurso ante su marido muerto y "así ubicada, esa mujer, al expresarse, se manifiesta como una excrecencia monstruosa, de fisiología y apariencia humana, pero virtualmente incapacitada para participar de modo activo en cualquier transformación del mundo" (Montero 113). Frente a ella, está Mario, su víctima, de quien su propio autor dice que "efectivamente, la muerte de Mario se produce por asfixia social. Es decir, Mario estalló antes de tiempo. No sé si recordarás que en la novela uno de sus amigos dice en el momento del entierro: 'No es un muerto, es un ahogado"" (Alonso de los Ríos y Delibes 171).

De acuerdo con estas lecturas, la historia narrada sería -entre otras cosas, también la historia de un adulterio, un retrato social de la pequeña burguesía española de provincias...- una parábola del eterno holocausto de la España laica, liberal y progresista que representa Mario, elevado en no pocos momentos a lo largo de la novela a una categoría mesiánica. Al igual que Cristo, Mario padeció y pereció por "tenértelas tiesas con los que mandan y ceder con los desarrapados" (Delibes, Cinco horas 171) y se convierte en víctima del fariseísmo de la sociedad -y, en particular, de su esposa- por no ceder a las tentaciones que, en este caso, adquieren la forma de promesas de puestos políticos, sobornos de alumnos y colaboraciones fijas en la poderosa prensa adepta al poder.

En la dilucidación de esta cuestión exegética se juega una buena parte de la valoración crítica de Cinco horas con Mario. Porque si estuviéramos de acuerdo con aquellos críticos primerizos, como Isaac Montero y Gonzalo Sobejano, pero también otros, los personajes de la novela estarían concebidos según un criterio estrictamente maniqueo y Mario se habría hecho depositario de todas las virtudes que la novela quería promover a través del perspectivismo irónico que distanciaba al autor de la narradora.

Para salvar a la novela de esta ingenua simplificación, interpretaciones posteriores han querido poner en cuestionamiento los roles de víctima y verdugo escenificados por Carmen y Mario, respectivamente. Carmen Martín Gaite, por ejemplo, opuso algunos matices a las bondades del esposo. El espacio del discurso, el despacho de Mario, es ese "recinto de excepción donde [Carmen] nunca reinó ni fue invitada a participar en nada, donde siempre se sintió como una intrusa" (391). Tirando de este hilo, Ann Davies ha destacado de Cinco horas con Mario 
Carmen's own capacity to expose an ideology that attempts to marginalize her. While her readings are at times inaccurate $[. .$.$] she does what Eco posits here as the 'un-$ masking' of an underlying code that Mario and his cronies have used to deny Carmen access to their world of thought, debate and learning, by using a coded language to which she does not have the key (1005).

Por tanto, esa excrecencia del sistema que es Carmen ha ido tornándose en un ser mucho más complejo, hasta aparecer no solo como un engendro de las estructuras de pensamiento del nacionalcatolicismo, sino también como una damnificada de la puritana e inexorable intelectualidad liberal progresista que representa su esposo. Este inusitado interés hacia la narradora de Cinco horas con Mario ha despojado definitivamente a su difunto esposo de todo protagonismo en la novela que lleva su nombre al tiempo que la crítica le arrebataba la inmaculada heroicidad que en un principio había aparentado tener.

Se ha producido, pues, un cambio en el horizonte de expectativas de los lectores de Cinco horas con Mario, los cuales han ido enriqueciendo con el paso de los años la comprensión de la novela. Mientras los primeros receptores efectivamente se complacían en ver reflejadas las insalvables diferencias entre las dos Españas en toda su radicalidad y arisca simplicidad, los lectores del presente prefieren - preferimos- una mayor problematización de las relaciones sociales de aquellos años. Así, con una habilidosa utilización de las estructuras narrativas, el novelista habría sido capaz de trascender aquel tiempo de consignas y posicionamientos claros y distintos. Mario ha dejado, de este modo, de resultarnos simpático:

este paladín de la modernidad, tal como lo presenta Delibes, resulta un tanto ridículo. Es un hombre de gestos más que de acciones. [...] Como padre de familia, Mario deja bastante que desear. [...] En sus relaciones con su mujer, Mario tiene además problemas de índole sexual (Alberich 219-220).

Es decir, que el hipotético distanciamiento irónico respecto de Carmen y la identificación sin reservas con Mario que la novela parece buscar resultan más difíciles de compartir por el lector actual. Claro que Carmen es mezquina, hipócrita, inculta y clasista, y Mario es tolerante, desprendido, culto y filantrópico. ¿Pero no es también pedante, inepto, incapaz de hacer feliz a su mujer, estúpido en sus elecciones, pusilánime, radical e incapaz de adaptarse al medio para transformarlo? Por el contrario, como ha resumido José María Alberich respecto del conato de adulterio cometido por Carmen,

esa aventurilla, si se hubiese consumado, no bastaría a destruir la imagen que se forma el lector de una Carmen fiel esposa y madre, trabajadora, abnegada, frente a un Mario distraído en sus musarañas de justicia social, pero poco atento a su familia y en el fondo, mucho más egoísta que su mujer. Malgré Delibes, Carmen resulta simpática y su difunto marido poco amable (220).

De ahí que la historia de la recepción de Cinco horas con Mario haya frustrado la tesis principal del libro (si aceptamos que, en realidad, la haya), porque los personajes se han emancipado de su autor. La historia los ha colocado a cada uno en su sitio. En definitiva, como ha venido a concluir Darío Villanueva, 
se trata de 'una gran novela de amor', en la que -y esto es algo muy importante que me interesa subrayar- la figura de Mario no es arquetípica e intachable, sino ambigua. Si Carmen es como es se debe en gran medida a los condicionamientos que la sociedad y una educación determinada imponen a su sexo y ella, mecánicamente, empieza ya a proyectar sobre su hija, alter ego suyo como Mario de su padre (307).

Incluso ocurre que asertos morales con los que la obra parece estar de acuerdo a través de la voz de Mario rechinan en la sensibilidad moral contemporánea. Tal es el caso, por ejemplo, de su aversión hacia toda técnica de planificación familiar, que a un lector actual -probablemente, mucho más laico que ese católico progresista que es el difunto personaje de la novela, posición intelectual que hoy ha desaparecido casi por completo del panorama político español- bien nos puede parecer muestra de irresponsabilidad. Por no hablar de su renuncia a hacerse cargo de las cuestiones materiales y aun de sus deberes conyugales. En definitiva, podría decirse que en las sucesivas lecturas generacionales de Cinco horas con Mario, la hermenéutica del texto ha ido enriqueciéndola mucho más allá de lo que la novela parecía que podía dar de sí. Se han encontrado ambigüedades y espacios de indeterminación donde los primeros lectores únicamente vieron una obra cerrada. La cuestión que planteamos en estas páginas es hasta qué punto esta lectura que rehabilita a Carmen y hace crecer una sombra de sospecha cada vez más tupida sobre Mario es legítima y no viola el significado denotativo del texto. Con otras palabras: ¿es posible abrir los sentidos de un discurso cuyo autor ha querido clausurar?

Para tratar de responder a este interrogante, hay que comenzar por señalar que los argumentos que Carmen repite una y otra vez se corresponden con un universo ideológico muy cerrado en el que se percibe con claridad la apropiación de los mensajes propagandísticos emanados de las estructuras de poder en la España de la posguerra. Se trata de una visión de la realidad uniforme y articulada, reflejo modélico del adiestramiento mediante el cual se buscó someter a los ciudadanos y anular su autonomía de criterio. En el caso de las mujeres, parece decirnos la novela, esta instrucción fue particularmente exitosa. Carmen reproduce aquellos lugares comunes como axiomas incontrovertibles y los reproches que dirige a su marido se basan, precisamente, en que este ha sido incapaz de percibir la perfecta armonía y el orden de las convenciones aprendidas de la autoridad. Varios críticos han descrito ya uno de los elementos psicológicos que articulan la historia de esta mujer: la esquizofrenia entre un mundo que cambia vertiginosamente y que parece arruinar las indisputables verdades en las que había sido adiestrada (Diverno 74).

El credo social de Carmen se caracteriza, principalmente, por dos certezas: una rígida convicción de las bondades del sistema de clases y la aceptación de las funciones tradicionales asignadas a los géneros. Por eso, uno de los recuerdos de Mario que más enfurece a Carmen es "que con la gente baja te achicaras, con lo sencillo que es darles cuatro voces y, en cambio, con la gente bien, inclusive con las autoridades, se te soltase la lengua y a desbarrar" (Delibes, Cinco horas 225). Por el contrario, para ella, prima la moral del servilismo con los de arriba y la arrogancia hacia los de abajo. En cuanto al sexismo de Carmen, es recurrente y ha sido ya suficientemente explicado por la crítica. El ideal de feminidad se reduce, a su juicio, a "saber pisar, saber mirar y saber sonreír" (76); una mujer es un "ser indefenso, [...] necesita que la dirijan" (175); y en 
cuanto a la formación de las mujeres, reproduce el dicho de que "mujer que sabe latín no puede tener buen fin" (81) con el que se previene ante los deseos de Mario de que su hija prosiguiera sus estudios. Sin embargo, con el cumplimiento de los XXV años de paz franquista, Carmen percibe atónita cómo un paleto como Paco se ha convertido en un señor. El mito de la cultura como clave diferenciadora entre clases pudientes y clases "bajas" ("artesanas", las denomina ella) se desbarata. El desarrollismo de los años cincuenta ha abierto las oportunidades de medro social a aquellos a quienes las convicciones clasistas de Carmen habían excluido de su propio ámbito. De ahí el conato de adulterio: en los meses anteriores a la guerra civil, ella había rechazado a Paco y se había casado con Mario. Aunque aquel era más atractivo, Mario era mejor partido (no el partido ideal, pero después de ver los riesgos de la soltería reflejados en el ominoso embarazo de su hermana Julia, Carmen y su familia lo habían aceptado como un mal menor). Pasados los años, con la irrupción de repentinos enriquecimientos a través de la especulación inmobiliaria y de la consecuente liberación de capitales, las clases sociales han desdibujado sus límites, abriéndose orificios por los que la posición relativa de Paco en el campo social ha experimentado un ascenso imprevisible, mientras Mario y ella misma, por el contrario, se han estancado o incluso han descendido. Si las relaciones con Paco estuvieron vetadas de jóvenes por prejuicios sociales, ahora los reparos morales no son suficientes para impedir la relación extramatrimonial, pues el atractivo que ejerce la posición de poder (económico, social...) de Paco lo legitima como amante. Sin embargo, a Carmen le enfurece que Mario no haya sido capaz de beneficiarse también de esa porosidad social y no haya querido adiestrarse en sus métodos de funcionamiento: el arribismo, el chantaje, la adulación y el mercadeo de favores. En este sentido, Cinco horas con Mario refleja perfectamente los mecanismos de una sociedad cuya armonía se basa en la aceptación común de la corrupción.

Este mismo cambio se percibe en el aspecto puramente político del espectro axiológico de Carmen. En este apartado hay cinco axiomas que Carmen repite en varias ocasiones: la preferencia por un gobierno autoritario; su nacionalismo patriotero; su concepción del ciudadano-súbdito que debe acatar la discrecionalidad de las fuerzas del orden; su inclinación por el sistema monárquico; y el mito de la guerra civil como cruzada o guerra de liberación. Aunque no se manifiesta de manera explícita sobre los gobernantes de España ni sobre la realidad política -pues su desinterés hacia todo aquello que vaya más allá de lo cotidiano y próximo la aparta de cualquier otra cuestión-su entendimiento es un reflejo acendrado de las consignas y motivos difundidos por la propaganda oficial. Cabe percibir en Cinco horas con Mario la disyuntiva que se abrió a la intelectualidad entre "comprensivos" (aquellos que abogaban por tender una mano al heterodoxo, al vencido, al proscrito, para integrarlo y reforzar así el sistema) e "intransigentes" (los inmovilistas que temían que esta integración acabara corrompiendo el sistema) ${ }^{1}$. Cinco

1 Ver, entre otros documentos al respecto, los artículos de Dionisio Ridruejo "Excluyentes y comprensivos" (Revista, 17 de abril de 1952, pp. 8-9) y "Meditación para el 1. . de abril" (Arriba, 1 de abril de 1953, pp. 1-2). 
horas con Mario refleja en qué medida esta dialéctica nunca resuelta por el Régimen no llegó a plantearse como un problema teórico en la ciudadanía. En cierta manera, Carmen representaría la intransigencia y Mario la comprensión. Pero la inestabilidad ideológica de la praxis política del franquismo afectó las creencias de ambos cónyuges. El ideal de diálogo que propugnaba Mario chocó con la realidad. Pese a todo, insistía en una tibia neutralidad con la que creía -sospechamos que igual que su autor-contribuir a acabar con el letal enfrentamiento de las dos Españas apostando por un repartimiento equitativo de culpas entre ambos bandos. Probablemente, nada haya más explicativo en este sentido que el hecho -escandaloso para Carmen- de que, a juicio de Mario, sus dos hermanos -el nacionalista y el republicano- "pensaban lo mismo" y que era igualmente posible encontrar "héroes de los dos lados" (Delibes, Cinco horas 143). Pero también a Carmen le causan estupor las mutaciones en los fundamentos políticos aprendidos, los cuales se tambalean a medida que evoluciona el franquismo. La retórica de los años sesenta, a menudo incluso asumida y corrompida por el Régimen, habla de valores nuevos como la tolerancia, el diálogo, la reconciliación nacional... que en realidad nunca excedieron un nivel puramente nominal.

En lo que respecta a las creencias religiosas de Carmen, un fanatismo integrista la hace intransigente con cualquier veleidad renovadora. La dimensión religiosa es una de las más presentes en el libro, cuyos elementos paratextuales, hay que recordarlo, nos indican que está escrito por un intelectual católico y dedicado a José Jiménez Lozano, otro intelectual conocido por su catolicismo aggiornato. Delibes comienza cada capítulo del monólogo con un breve texto de la Biblia que ha sido subrayado por Mario y que encauza los disparates mentales de Carmen. Esta ha sido también permeable a las consignas del modelo de religión impuesto en España por el nacionalcatolicismo. Pero incluso el ministerio de lo trascendente e intocable ha mudado en aquel revolucionario último decenio. La tolerancia, el compromiso social, el ecumenismo... son conceptos asumidos por el catolicismo postconciliar que profanan los preceptos religiosos aprendidos por Carmen.

La cultura es otra de las categorías prominentes en la escala de valores de Carmen, aunque en este caso, el acervo de textos alusivos que Delibes despliega en Cinco horas con Mario es mucho menos explícito. Hay dos concepciones del mundo de la cultura claramente confrontadas: la de su padre, intelectual monárquico y católico, cuya firma es recurrente en el $A B C$; y la de su marido, escritor de novelas sociales y columnista en un periódico liberal. La cultura de su padre es un signo de jerarquía social. En virtud de este estatuto heredado, Carmen desprecia al Paco de los años treinta porque comete risibles barbarismos lingüísticos. Al mismo tiempo, admira las facultades intelectuales de su padre, que mide de acuerdo con el reconocimiento público que con ellas ha alcanzado. Caso contrario es el de Mario, que ha malogrado sus aptitudes, poniéndolas al servicio de lo que ella considera reparos o prevenciones morales y políticas. A causa de esta debilidad intelectual, Mario se vio en la necesidad de recurrir a su suegro para que le redactara la Memoria con la que alcanzó la cátedra del Instituto en que trabaja. Sin embargo, en los años sesenta también la cultura aparece trastornada. La dignidad de Mario como escritor e intelectual, por ejemplo, está lastrada a los ojos de Carmen por dos pesadas rémoras que, en cierta manera, se oponen entre sí: por un lado, el experimentalismo literario al 
que somete a su escritura, el cual la hace opaca a sus ojos y a sus entendederas, tanto como su predilección exclusivista por temas graves que invariablemente caen en lo metafísico, moral y social; por el otro, su renuncia a las prebendas sociales que su posición de intelectual merece ante los demás, sobre todo, ante los subalternos. Carmen se siente excluida del primer rasgo de la cultura de Mario por su propia poquedad intelectual; y del segundo, por un acto de voluntarismo que le impide renunciar a la superioridad que su marido podría haber disfrutado como catedrático de instituto, periodista, conferenciante y escritor.

Finalmente, el retrato de Carmen se complementa con un discurso de carácter moral. Para ella, el decálogo parece reducirse a un solo imperativo, que es el de la castidad. Pero no se trata de una castidad militante, como la que Mario demostró durante su noviazgo, su noche de bodas y aun durante su vida conyugal -negándose a ninguna práctica anticonceptiva, ni siquiera el permitido método Ogino--, sino de reiteradas pruebas de mojigatería. Sus juicios acerca de las mujeres de ideas avanzadas durante los años treinta y cuarenta están llenos de alusiones despectivas, sobre todo, si se trata de Transi y de su hermana Julia. Sin embargo, también en este sentido su concepción del mundo se ve atropellada por el paso del tiempo. La década de los sesenta ha traído una liberalización de las costumbres, con el turismo, etcétera. Y aunque ella se aferra a los dogmas morales aprendidos en su juventud, se ve arrastrada por los nuevos tiempos hasta alcanzar los umbrales del adulterio.

Carmen representa la esquizofrenia generalizada que pudieron experimentar los miembros de su generación al ver cómo las piezas del edificio argumental en el que habían sido educados se desmoronaban lentamente y su enunciación quedaba en una mera fórmula. Mucho más, teniendo en cuenta que los patrones no habían pretendido formar ciudadanos autónomos, sino súbditos programados para la asimilación de dogmas únicos. Cuando los órganos de poder en España se vieron obligados a traicionar aquellos dogmas para sobrevivir, las estructuras de pensamiento de los hombres y mujeres que no habían sometido a crítica aquellos principios eran tan rígidas que terminaron quebrándose. Carmen no comprende que la Iglesia católica acepte con normalidad otras creencias, que un don Nadie detente signos de prestigio social que a ella se le niegan, que la cultura no la proteja, sino que la excluya, que alguien ose promover el diálogo con heterodoxos sobre los que un día solo se dictaba la muerte o el destierro... El dictum que prescribía que todo cambie para que todo siga igual le permitió subsistir al estado franquista pero creó patologías en la sociedad e incoherencias en su modo de ver la realidad. La posición en el mundo de Carmen -como ajustado resultado del franquismo sociológico- se ha visto seriamente perjudicada por estos cambios.

Con todo ello, ¿es posible descubrir una tesis en la novela? Primero debemos definir qué entendemos por "novela de tesis". Para poder calificar como tal a una obra narrativa, deberíamos encontrar los siguientes rasgos: personajes arquetípicos que encarnen con suficiente nitidez principios contrapuestos; una trama ejemplarizante, que no siempre debe terminar felizmente, pero de la que se pueda obtener una conclusión moral que se sigue del repertorio de acontecimientos; lectores implícitos que penetren en los significados e identifiquen su código moral con el de uno o varios personajes; máxima reducción 
del lenguaje connotativo; y una estructura compositiva en la que queden suprimidos los atisbos de ambigüedad.

En el caso de Cinco horas con Mario, los elementos discursivos parecen prevenir ante la novela de tesis. El perspectivismo irónico que urde la estructura de la novela deja amplios espacios para la indeterminación y para la complejidad ${ }^{2}$. Y aunque Carmen se nos hace depositaria de vicios poco aceptables, tal vez al lector de hoy en día tampoco Mario le resulte arquetipo de bondades morales y políticas, como hemos establecido más arriba. Todas estas dudas se desvanecen junto con la ironía, el perspectivismo y todo atisbo de ambigüedad, en el epílogo que sigue a la meditación de Carmen. En estas últimas páginas, un prepotente Mario hijo se dirige a su madre, pero también al lector con un tono de sermón petulante. Por si no había quedado suficientemente explicada la tesis del libro y por si el lector no había sido capaz de discernir los significados ideológicos que pretendía demostrar Delibes, se introduce la figura de este joven que perora acerca de los comportamientos sanos y los patológicos que pueden seguir los ciudadanos. $\mathrm{H}$. L. Boudreau describió bien este viraje en el tono narrativo de la novela: "such an overt statement, following upon the heels of the subtly constructed ironic monologue of the novel proper, is grossly anti-aesthetic and seems to represent on Delibes' part a lack of faith in his own ironic art or a disbelief in his readers' ability" (15).

Convengo con esta cita en que la intervención de Mario es un desacierto nada trivial que, definitivamente, convierte Cinco horas con Mario en una novela de tesis. El lector siente en estas páginas finales que el discurso novelesco ha desistido de apelar a su

2 El recurso a este monólogo irónico no oculta a cualquier lector las intenciones de la novela, pero, sin embargo, a Delibes le valió para sortear la censura, como él mismo ha explicado en varias ocasiones (por ejemplo, en Alonso de los Ríos y Delibes 104). Como moraleja de esta feliz solución discursiva, Delibes se apuntó a la tesis pro domo sua y de todos los narradores peninsulares bien vistos por el Régimen de que la censura había sido incluso beneficiosa para la creación literaria pues "acaba por ser un estímulo de la imaginación del escritor que le lleva a esquivar el toro y a buscar soluciones inteligentes para decir lo que pretende decir sin ofenderla ni encabritarla" (Delibes, España 161). No puedo evitar hacer un comentario negativo a este juicio - por otra parte tan recurrente- que quiere hacer pasar el vicio por virtud. Si un autor precisa de estas cortapisas para "estimular" su talento, sospecho que tal talento es demasiado limitado y solo puede manifestarse en tiempos de miseria cultural. Por tanto, hacer pasar esa grave patología de la literatura española del siglo XX -de la que solo se libraron quienes escribieron sin hacer cálculos de oportunidad, como Luis Martín Santos o Juan Benet, o quienes prefirieron escribir en libertad y publicar sus novelas en el extranjero, como los exiliados, Juan Marsé o Juan Goytisolo- como un "estímulo", me parece una impostura ante los lectores. En cualquier caso, es cierto que gracias al mecanismo del monólogo pudo sortear el juicio de un censor que, sospecho, estaba bien predispuesto hacia Delibes y quiso ver que en el monólogo de Carmen "predomina el humorismo crítico en labios de una mujer española corriente, que tiene buen sentido y que no es o no sabe ser corrosiva" (Archivo General de la Administración, Alcalá de Henares). 
inteligencia y que han asido su mano para llevarlo a una moraleja inequívoca. El mismo Delibes lo explicó con meridiana claridad:

Junto a la contraposición de caracteres de Mario y Menchu, Altés vio en la figura del hijo la esperanza. Y esto es lo que yo pretendí. El chico habla a su madre, en las últimas páginas del libro, en un tono afectuoso y trata de hacerle comprender que los buenos no son los de la derecha ni los malos los de la izquierda, sino que todos, a la derecha y a la izquierda, somos buenos y malos, que lo que hay que hacer es tratar de hablar y comprenderse, abrir las ventanas en un país que no las abre desde siglos. En fin, esta actitud del chico, de reconciliación, opuesta a nuestro tradicional maniqueísmo, comporta un rayo de esperanza. Si los jóvenes fueran así, es evidente que pasado mañana dejarían de existir Menchus en el país (Alonso de los Ríos y Delibes 78).

Hay pues una intención clara en el libro: promover que existan muchos Marios y desaparezcan todas las Menchus. Es suficientemente llamativo el hecho de que en esta entrevista Delibes emplease el mismo lenguaje con que había hecho hablar a Mario hijo, lo que demuestra hasta qué punto llegó la dependencia de los personajes respecto de su autor en el caso de Cinco horas con Mario. El autor de esta novela ha utilizado los instrumentos de la novela para asumir una actitud mesiánica, un papel de predicador contra los vicios que impiden la normalización de la sociedad española de su tiempo. Al margen del acuerdo o desacuerdo con sus tesis, tal actitud resulta ajena al arte de la novela tanto hoy como en los años en que se publicó por primera vez la historia de Carmen y Mario.

Cabe una interpretación que salve la novela según la cual Cinco horas con Mario trataría de la contradictoria situación en que se ve el intelectual que decide no claudicar ante un sistema social y político opresivo. La dialéctica entre el posibilismo (hacer concesiones parciales ante un sistema totalitario para poder transformarlo gradualmente) y el imposibilismo (negarse a cualquier claudicación y apostar por una subversión radical del sistema patológico) estaba en el origen de las discusiones en un momento en que las bases intelectuales del franquismo se habían tambaleado y muchos franquistas de primera hora se preguntaban cómo oponerse al sistema que ellos mismos habían ayudado a configurar. El debate se haría público años después, en la famosa polémica que mantuvieron Alfonso Sastre y Antonio Buero Vallejo ${ }^{3}$. Mario representaría bien uno de los dos polos, el que aúna la más incorruptible honradez con la incapacidad más recalcitrante. Este espíritu contradictorio es el que, a través de las increpaciones de Carmen, quiso tal vez reflejar Delibes en su novela. Mario, como todo aquel que lleva sus posturas intelectuales a la honestidad más extremada, es a un tiempo admirable y ridículo,

3 Alfonso Sastre puso de actualidad el término en su artículo "Teatro imposible y pacto social" (1960), en donde se definían claramente ambas posturas, adaptándolas a las circunstancias particulares del teatro español de la época y añadiendo a las condiciones políticas las restricciones del mercado. Al texto de Sastre siguieron, en el número siguiente de Primer Acto, la respuesta de Antonio Buero Vallejo, a quien se había señalado como prototipo de autor de un teatro posibilista, y, en el siguiente, la contrarréplica de Sastre. 
leal y testarudo, idealista y débil, atractivo y tedioso. Sus libros serían revolucionarios si alguien los leyera. Pero es incapaz de asumir cuáles son las reglas del juego que rigen para quienes quieren verdaderamente reequilibrar un estado de cosas anómalo. Sin embargo, parece decirnos Delibes, la alternativa a este intelectual imposibilista que es Mario estaría únicamente en la alienación de Carmen, entregada por entero a unos códigos impuestos.

Otra interpretación redentora de la novela es la que propone, por ejemplo, Miguel García-Posada, según la cual, "el propósito básico de Delibes no fue político, [sino] que su intención de fondo residió en mostrar el discurrir contradictorio de dos vidas en el marco de la España de posguerra" (115). Según esta visión, la novela de Delibes habría estado lastrada por una lectura unilateral ocasionada por el contexto social en que se publicó, que llevó a la progresía española a reducir Cinco horas con Mario a "su condición de texto de combate" (120). Más allá de estos reduccionismos, la novela trascendería el tiempo histórico en que fue publicada como la historia trágica de un matrimonio, condenado por la incomunicación entre dos existencias irreductibles a causa de la exhibición de sendos lenguajes que los mantienen en esferas irreconciliables. Sin embargo, Carmen es un personaje demasiado arquetípico de la sociedad franquista para encarnar un buen personaje novelesco. Su frustración, como hemos querido mostrar en las páginas precedentes, procede de una doctrina nacional que la había alienado, animalizado y empequeñecido. Esta es precisamente la fuerza del discurso de Delibes: su crítica política en el más amplio sentido del término. Pero también su debilidad como novela: Carmen no sobrepasa la categoría de caricatura en manos de un escritor moralista que en 1966 tenía ideas demasiado inconcusas en lo tocante a moral, sociedad, política, religión y aun literatura. Y lo que es peor: que lejos de plantear dudas y asombros no dejó pasar la oportunidad de ostentar sus certidumbres a los lectores de su novela.

Con ello volvemos a las primeras páginas de este trabajo: ¿qué queda de esta novela sin su fondo ideológico? ¿Podemos conformarnos con el brillante ejercicio de sociolingüística y dialectología encarnado en Carmen Collado? ¿O con la mera descripción costumbrista de las frustraciones de un matrimonio de provincias? La respuesta es para mí aún más clara si la situamos en el contexto literario de su época. Como Tiempo de silencio, Si te dicen que caí, Volverás a Región o Señas de identidad, la novela de Delibes se alimenta de la perplejidad existencial inducida por un pensamiento único que, sin embargo, no muestra sino flagrantes incoherencias. Pero, a diferencia de tan ilustres coetáneas, los atributos estilísticos del texto no bastan para dotarlo de la complejidad que podría haber hecho de Cinco horas con Mario un hito en nuestra historia literaria.

\section{BIBLIOGRAFÍA}

Alberich, José María. "Cinco horas con Mario o el tiro por la culata". Minervae Baeticae. Boletín de la Real Academia Sevillana de Buenas Letras 32 (2004): 215-221.

Alonso de los Ríos, César y Miguel Delibes. Conversaciones con Miguel Delibes. Barcelona: Destino, 1993. 
Boudreau, Harold L. "Cinco horas con Mario and the Dynamics of Irony". Anales de la Novela de Posguerra 2 (1977): 7-17.

Davies, Ann. "Who is the Model Reader of Delibes's Cinco horas con Mario?". The Modern Language Review 94 (1999): 1000-1008.

Delibes, Miguel. Cinco horas con Mario. Barcelona: Destino, 1966. 2004.

España 1936-1950. Muerte y resurrección de la novela. Barcelona: Destino,

Diverno, Melissa. "Dictating Fictions: Power, Resistance and the Construction of Identity in Cinco horas con Mario". Bulletin of Spanish Studies 81 (2004): 49-76.

García-Posada, Miguel. “Cinco horas con Mario: una revisión”. Miguel Delibes. El escritor, la obra y el lector. Coord. Cristóbal Cuevas García. Barcelona: Anthropos, 1992. 115129.

Martín Gaite, Carmen. Agua pasada. Barcelona: Anagrama, 1993.

Montero, Isaac. "El lenguaje del limbo". Revista de Occidente 61 (1968): 101-117.

Ridruejo, Dionisio. "Excluyentes y comprensivos". Revista (17 de abril de 1952): 8-9. "Meditación para el 1. ${ }^{\circ}$ de abril". Arriba (1 de abril de 1953): 1-2.

Sobejano, Gonzalo. Novela española de nuestro tiempo. Madrid: Prensa Española, 1970.

Villanueva, Darío. Estructura y tiempo reducido de la novela. Barcelona: Anthropos, 1994.

Palabras Clave: ideología, franquismo, novela de tesis, perspectivismo irónico.

KEY WORDS: ideology, Francoism, thesis novel, ironic perspective. 